\title{
Reviving Previous Therapeutics by Recombinant Anaerobic Bifidobacteria
}

\author{
Ikuko Taira*, Yuichiro Taira, Masakazu Kato, Yoshimi Shimizu, Katuhiro Isoda, Hiromi Saitou and Isao Ishida \\ Department of Pharmaceutical Sciences, Japan
}

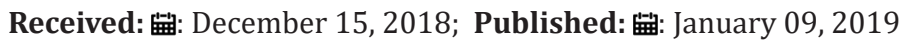

*Corresponding author: Ikuko Taira, Department of Pharmaceutical Sciences, 4-21-2 Nakano Nakano-ku Tokyo 164-8530, Japan

\begin{abstract}
Anaerobic bacteria such as clostridia have gained attention for use in anti-cancer therapies. They selectively invade tumor tissue and grow in the hypoxic environment surrounding the tumor cells. Bacterial infection activates host immunity in the tumor tissue and induces tumor regression. Anaerobes can be utilized to carry drugs to the tumor tissues using recently developed genetic engineering technologies. In this review, we introduce cancer therapies involving the use of bacteria and our recent research on a drug delivery system for cancer treatment using recombinant bifidobacterium, a naturally non-toxic anaerobe.

Keywords: Bifidobacterium; Drug Delivery System; Anti-Cancer Therapy; Immunotoxin; TRAIL

Abbreviations: S. Typhimurium: Salmonella Enterica Serovar Typhimurium; MDSCs: Myeloid-Derived Suppressor Cells; L. Monocytogene: Listeria Monocytogenes; dPEA: pseudomonas Exotoxin Subunit A Lacking its Receptor Binding Site; VHH: Variable Domain of Heavy Chain of Heavy-Chain Antibody; EGFR: Epidermal Growth Factor Receptor; TRAIL: Tumor Necrosis Factor-Related Apoptosis-Inducing Ligand; TR: TRAIL Receptor; R\&D: Research and Development
\end{abstract}

\section{Introduction}

\section{Applications of Bacteria for Treatment Cancer}

For the drug discovery and development, microorganisms have been indispensable as sources for screening seed compounds [1] and have been used to manufacture biopharmaceuticals through genetic engineering in the past decade [2]. Additionally, cancer immunotherapy, which has recently been examined in terms of immune-checkpoint inhibitors, has achieved cancer remission by activating human host immunity through bacterial infection [3]. In the 19th century, the American surgeon William B. Coley discovered the anti-cancer effect of erysipelas. He then performed cancer treatment with the heat-killed bacterial mixture known as Coley's toxin [4], which induced regression of tumor tissues. This therapy is based on the release of immune suppressionrelated molecules in patients with cancer [5], and therefore causes pathological conditions such as fever or inflammation. Thus, the bacterial preparation should be administered to the topical tumor site or intratumorally. This concept has been applied to intravesical Bacillus Calmette-Guérin treatment for non-muscle invasive bladder cancer and has shown efficacy comparable to those of chemotherapies [6,7].
Live bacteria have also been used in studies of cancer treatment [8]. Clostridia have a long history of investigation, including the use of their spores as anticancer agents, dating to the 1950s [9]. Salmonella enterica serovar Typhimurium is known to specifically colonize tumor tissues and invade tumor cells [10]. The antitumor effects produced by these bacteria occur via induction of host immune responses even if toxicity is attenuated or eliminated $[10,11]$, and may be enhanced by their topical administration to tumor tissues $[12,13]$. Recently, S. Typhimurium was shown to decrease P-glycoprotein, which is involved in tumor multidrug resistance. A Salmonella-mimicking nanoparticle was developed to overcome multidrug resistance in tumor cells [14]. Listeria monocytogenes can enter antigen-presenting cells and induce powerful immune responses. Accordingly, L. monocytogenes was genetically modified to produce cancer-specific antigens and has been used to develop vaccines for cancer therapy [15]. This species also survives in tumor tissues and myeloid-derived suppressor cells (MDSCs) [16], causing the release of immunosuppression-related molecules by MDSCs [17]. Thus, recombinant L. monocytogenes is being adapted for use in therapeutic cancer vaccinations as an antigen carrier and adjuvant $[15,18]$. 


\section{Potential of Anaerobes as Drug Delivery Carriers to Tumor Tissues}

Anaerobic bacteria, including clostridia, S. Typhimurium, and L. monocytogenes, are distributed specifically into solid tumor tissues through enhanced permeability and retention effects [19]. Intravenously administered anaerobes invade tumor tissues from leaky tumoral blood vessels, after which they can survive and proliferate specifically in the intratumoral hypoxic environment [20] (Figure 1). Through progress in genetic engineering, these bacteria are considered as vectors for carrying anticancer proteins into tumor tissues [21-23]. Bifidobacteria are also wellknown obligate anaerobic bacteria that commonly inhabit the human and animal intestines. They are non-toxic gram-positive bacteria, and thus have no risk of endotoxin shock associated with their intravenous administration. Genetic modification has been difficult in most bifidobacterial cells [24]; however, gene transformation [25,26] and knock out [27] are practical methods in some bifidobacterial strains with high transformation efficiency [28]. Based on these advantages, recombinant bifidobacteria that express cytosine deaminase to convert prodrug 5-fluorcytosine into active 5-fluoruracil in tumor tissues have been developed [29].

\section{Tumor-bearing mouse}

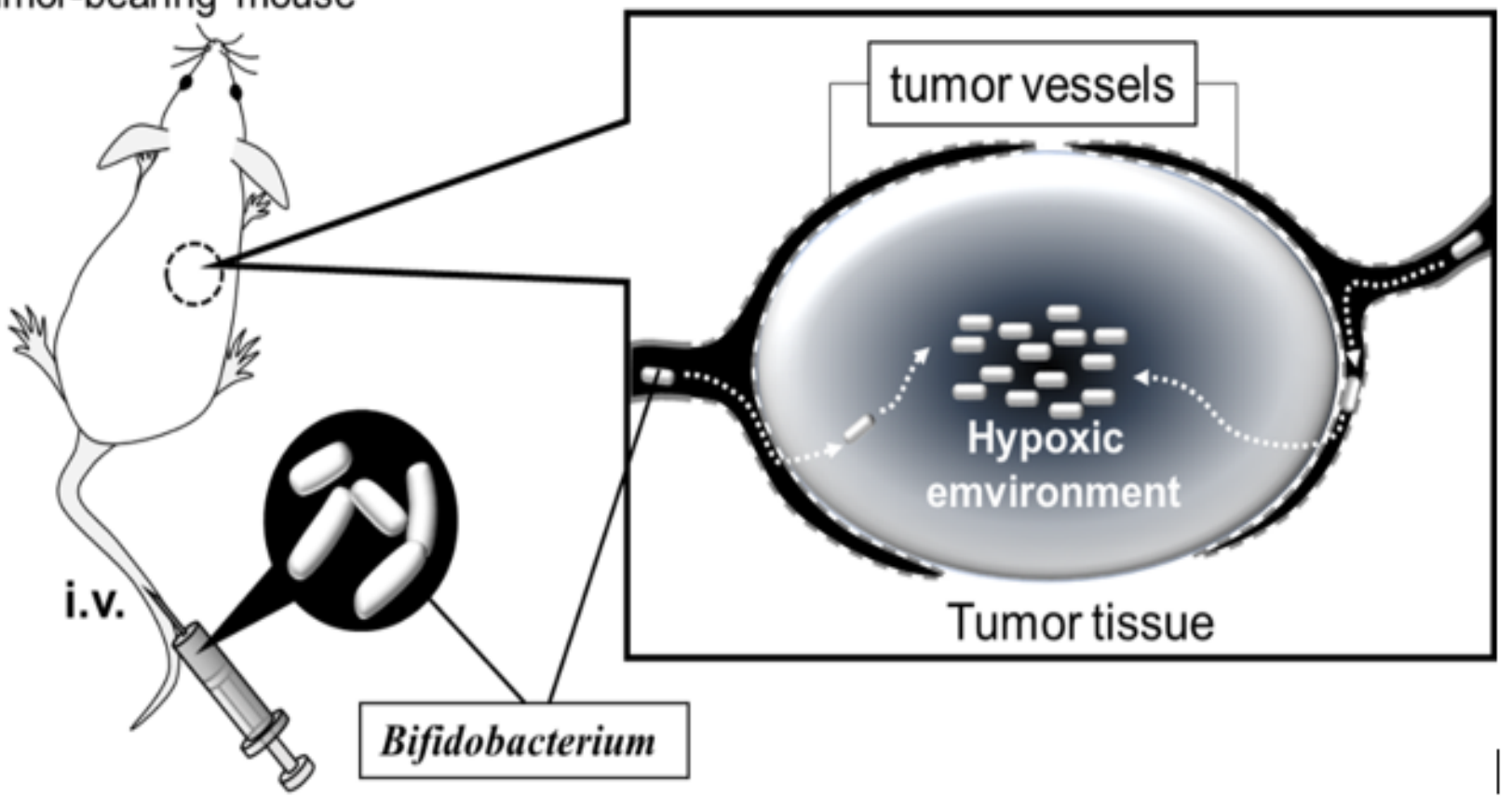

Figure 1: Bifidobacteria as a drug delivery system for intratumorally hypoxic environment.

Intravenously administered anaerobes selectively enter the tumor tissue and accumulate and proliferate in the hypoxic environment. Bifidobacteria are non-toxic obligate anaerobes and can be utilized as drug delivery carriers to tumor tissue.

We established a system for delivering proteins into tumor tissue using recombinant bifidobacteria expressing physiologically active proteins. First, we aimed to re-examine the use of immunotoxins [30]. Immunotoxins did not show enough effectiveness during their clinical tests in the 1980s because of their systemic adverse effects and induction of neutralizing antibodies; thus, it is necessary to develop methods for their delivery into tumor tissues. To achieve this, we employed a toxin-releasing bifidobacteria as carrier and constructed the gene of pseudomonas exotoxin subunit A [31] lacking its receptor binding site (dPEA) to avoid invasion of toxin molecules into normal cells [32]. This subunit was fused with a bifidobacterial secretary peptide sequence and variable domain of heavy chain of heavy-chain antibody ( $\mathrm{VHH}$ ) gene of the camelid single-chain antibody [33] (Figure 2) against epidermal growth factor receptor (EGFR). EGFR is a well-known molecular target for cancer treatment [34]. EGFR is also suitable as an immunotoxin target because it is internalized in cells upon binding to ligands or agonists [35]. This VHH-dPEA gene construct was introduced into bifidobacterial cells, causing them to secrete VHH-dPEA fusion proteins and was named as the 8C7 toxin. The cloned 8C7 toxinsecreting bacteria exhibited anti-tumor effects when administered intravenously into tumor-bearing mice [36]. The anti-tumor effect of 8C7 toxin was comparable to that of gefitinib [36, 37] (Figure 3), and adverse effects such as weight loss or hepatic dysfunction were not observed. 


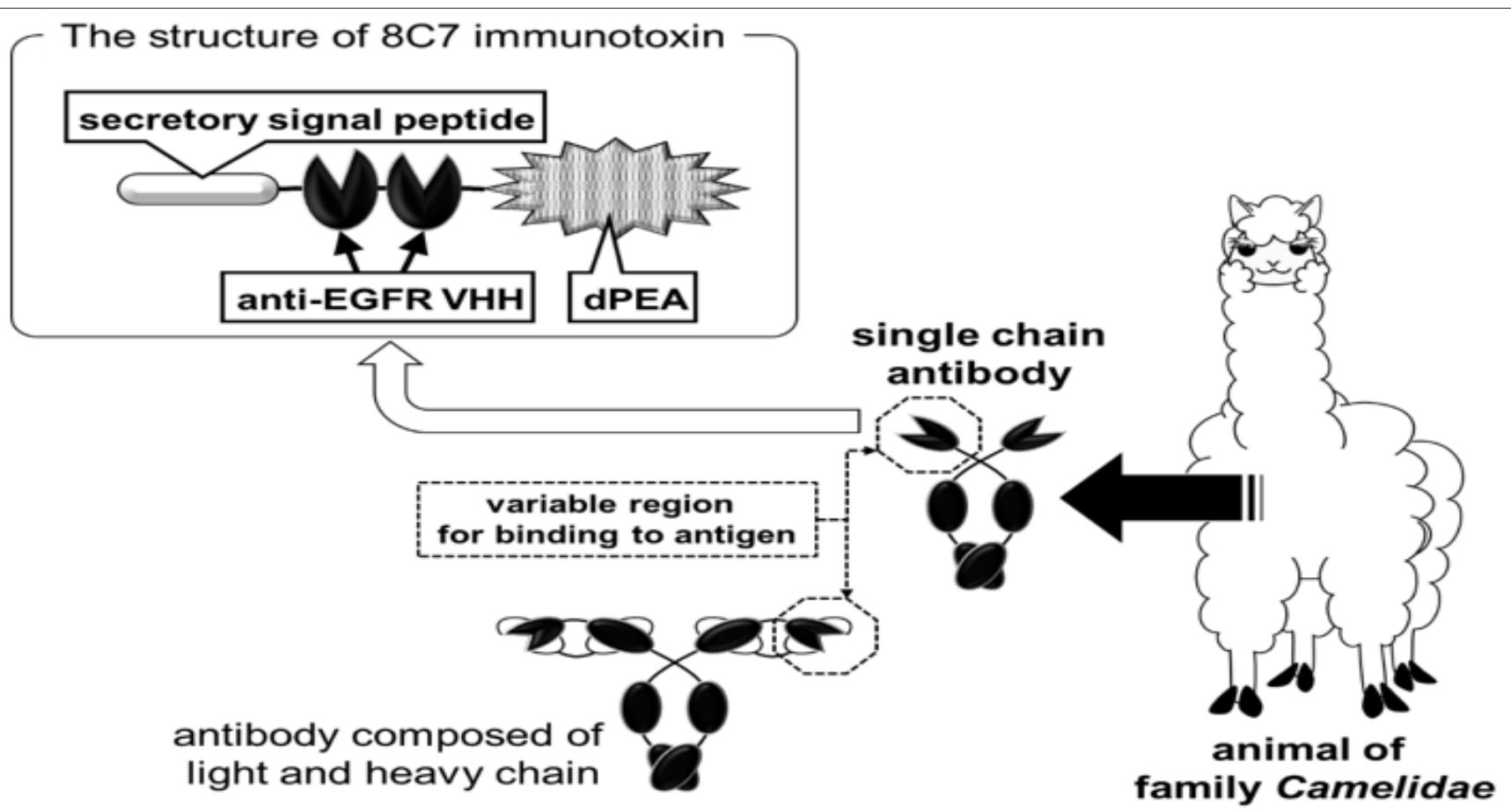

Figure 2: Immunotoxin for the expression in bifidobacteria

We utilized camelid VHH against EGFR to construct the immunotoxin. Unlike the variable region of a general antibody molecule composed of light and heavy chains, VHH derived from a camelid single-chain antibody can bind to an antigen as a single polypeptide. Because $\mathrm{VHH}$ is a very small molecule with excellent chemical stability, its application can lead to the development of pharmaceutical products.

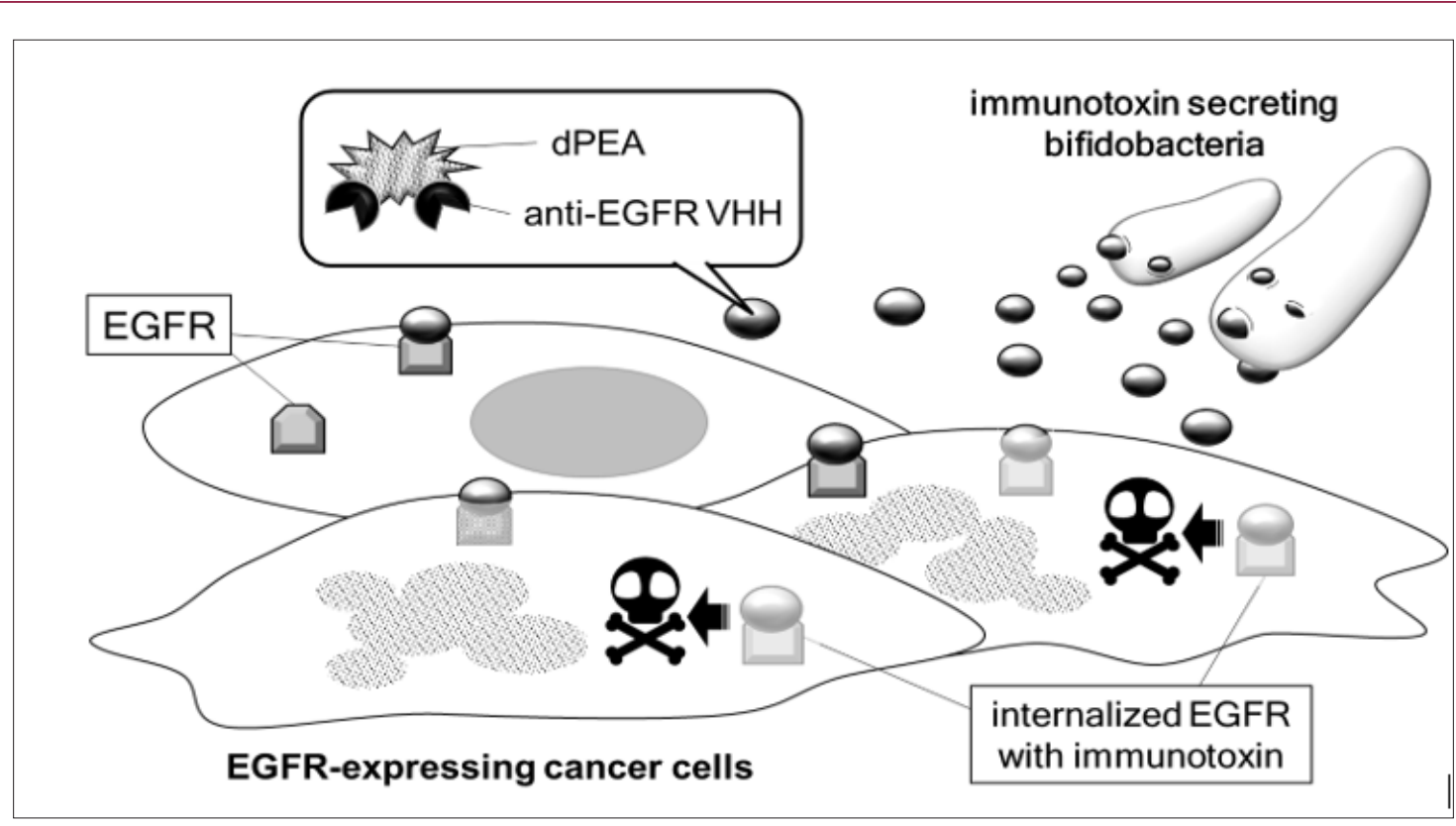

Figure 3: Schematic image of tumor cell-selective cytotoxicity by $8 \mathrm{C} 7$ immunotoxin

Recombinant bifidobacteria administered directly into bloodstream accumulate selectively in tumor tissues and secrete 8C7 immunotoxin. 8C7 immunotoxin molecules bind to EGFR expressed on tumor cell surface, and then invade tumor cells by endocytosis. The dPEA portion of 8C7 immunotoxin causes cell death by inhibiting protein synthesis. 
We next targeted the receptor for tumor necrosis factor-related apoptosis-inducing ligand (TRAIL). TR1 and TR2 are subtypes of the TRAIL receptor (TR) and transduce apoptotic signals [38,39]. There are at least six subtypes of TR, some of which act as decoy receptors. To circumvent decoy receptors, agonist antibodies against TR1 or TR2 were developed as anti-cancer agents. Unfortunately, these agonist antibodies based on immunoglobulins with two antigen-recognition sites showed low effectiveness, as TRs transduce apoptotic signals in a trimer form; thus, multivalent antibodies were developed (Figure 4). The multivalent antibodies exhibited high agonistic activity in preclinical tests, while in clinical trials, they caused sever hepatic dysfunction [40] because of the sensitivity of hepatic cells to TRAIL [41]. To establish safe and effective multivalent TR agonist antibodies, a drug delivery system specific to tumor tissue is required. We predicted that a bifidobacterial delivery system could be used to avoid the adverse effects of TR agonist antibodies and prepared recombinant bifidobacterial clones secreting trivalent TR1 or tetravalent TR2 agonistic antibodies with VHH [42]. These clones showed anti-tumor effects in tumor-bearing mice following intravenous administration, and critical adverse effects were not observed during the experiment.

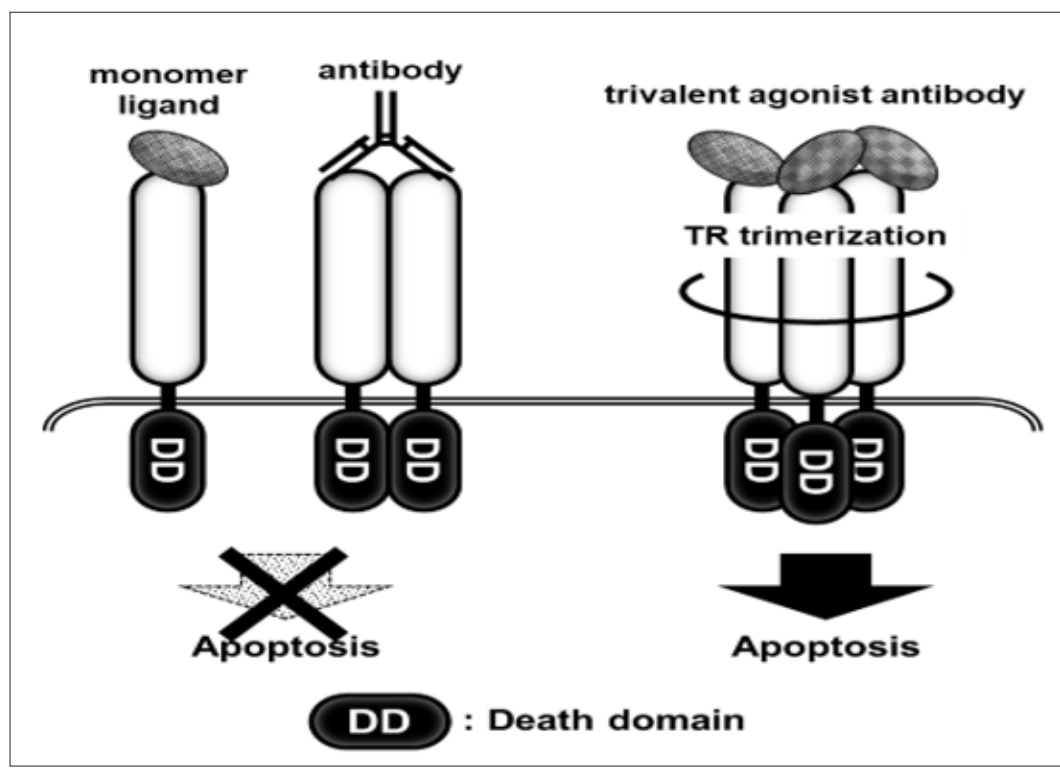

Figure 4: Induction of cell death by trimer TR agonist antibody

When TRs bind with their ligands, they form into homo trimers and then induce apoptosis. Previous TR agonist products did not allow TRs trimerization because they were monomer ligands or agonist antibodies with two antigen-recognizing sites. In contrast, trivalent TR agonist antibodies simultaneously recognize three TRs in a single molecule, thus inducing cell death efficiently.

\section{Conclusion and Further Possibilities}

As described above, the recombinant bifidobacteria are valuable as drug delivery carriers based on their selectivity for tumor tissues and safety. Additionally, their target molecules to fight tumor cells can be changed by varying their exogenous genes. Our system can be used to overcome the limitation of anticancer protein preparations discarded during their development because of their systemic side effects or poor tumor-specificity. Increases in pharmaceutical research and development (R\&D) expenditures have become a serious problem among factors increasing medical expenses [43]. Additionally, the probability of successfully developing new medicines has decreased [44], and thus large numbers of pharmaceutical R\&D projects are suspended or discontinued in preclinical or clinical trials.

Some products developed through such projects were verified to be safe and effective, and thus have been converted into other new medicines by drug repositioning $[45,46]$ or by combining technologies such as antibody-drug conjugation $[47,48]$. These drug-reuse approaches, including our bacterial product, are expected to reduce the costs and time required for drug development. The most conventional procedures for manufacturing protein-based biopharmaceuticals require large-scale systems for protein purification and production using animal cells and costly culture media. In contrast, our recombinant bifidobacteria are the protein producing system and can be administered to patient as bacteria themselves without protein purifying process. The massproduction of bifidobacteria can be achieved at a reasonable cost because they can grow in simple and low-cost medium. Therefore, a bifidobacterial delivery system substantially contribute to lowering medical expenditures both in the biopharmaceutical R\&D process and manufacturing process.

\section{References}

1. Farnet CM, Zazopoulos E (2005) Improving Drug Discovery from Microorganisms from Natural Products: Drug Discovery and Therapeutic Medicinem. In: Zhang L, Demain AL (Eds.). pp. 95-106. 
2. H Akabane (2018) The trends of biologics seen from aspects of production and dosage form. Pharm Thch Japan 34(10): 2015-2020.

3. Mellman I, Coukos G, Dranoff G (2011) Cancer immunotherapy comes of age. Nature 480(7378): 480-489.

4. Wiemann B, Starnes CO (1994) Coley's toxins, tumor necrosis factor and cancer research: a historical perspective. Pharmacol Ther 64(3): 529564.

5. Whiteside TL (2006) Immune suppression in cancer: effects on immune cells, mechanisms and future therapeutic intervention. Semin Cancer Biol 16(1): 3-15.

6. Malmström PU, Sylvester RJ, Crawford DE, Friedrich M, Krege S, et al. (2009) An individual patient data meta-analysis of the long-term outcome of randomised studies comparing intravesical mitomycin $\mathrm{C}$ versus bacillus Calmette-Guérin for non-muscle-invasive bladder cancer. Eur Urol 56(2): 247-256.

7. Ye Z, Chen J, Hong Y, Xin W, Yang S, et al. (2018) The efficacy and safety of intravesical gemcitabine vs Bacille Calmette-Guérin for adjuvant treatment of non-muscle invasive bladder cancer: a meta-analysis. Onco Targets Ther 11: 4641-4649.

8. Forbes NS (2010) Engineering the perfect (bacterial) cancer therapy. Nat Rev Cancer 10(11): 785-794.

9. Minton NP (2003) Clostridia in cancer therapy. Nat Rev Microbiol 1(3): 237-242.

10. Hernández Luna MA, Luria Pérez R (2018) Cancer Immunotherapy: Priming the Host Immune Response with Live Attenuated Salmonella enterica. J Immunol Res 2018: 2984247.

11. Staedtke V, Roberts NJ, Bai RY, Zhou S (2016) Clostridium novyi-NT in cancer therapy. Genes Dis 3(2): 144-152.

12. Roberts NJ, Zhang L, Janku F, Collins A, Bai RY, et al. (2014) Intratumoral injection of Clostridium novyi-NT spores induces antitumor responses. Sci Transl Med 6(249): 249 ra111.

13. Kocijancic D, Felgner S, Schauer T, Frahm M, Heise U, et al. (2017) Local application of bacteria improves safety of Salmonella -mediated tumor therapy and retains advantages of systemic infection. Oncotarget 8(30): 49988-50001.

14. Mercado Lubo R, Zhang Y, Zhao L, Rossi K, Wu X, et al. (2016) A Salmonella nanoparticle mimic overcomes multidrug resistance in tumours. Nat Commun 7: 12225 .

15. Flickinger JC, Rodeck U, Snook AE (2018) Listeria monocytogenes as a Vector for Cancer Immunotherapy: Current Understanding and Progress. Vaccines (Basel) 6(3): E48.

16. Gabrilovich DI, Nagaraj S (2009) Myeloid-derived suppressor cells as regulators of the immune system. Nat Rev Immunol 9(3): 162-174.

17. Chandra D, Jahangir A, Quispe Tintaya W, Einstein MH, Gravekamp C (2013) Myeloid-derived suppressor cells have a central role in attenuated Listeria monocytogenes-based immunotherapy against metastatic breast cancer in young and old mice. Br J Cancer 108(11): 2281-2290.

18. Le DT, Wang Gillam A, Picozzi V, Greten TF, Crocenzi T, et al. (2015) Safety and survival with GVAX pancreas prime and Listeria Monocytogenes-expressing mesothelin (CRS-207) boost vaccines for metastatic pancreatic cancer. J Clin Oncol 33(12): 1325-1333.

19. Maeda H, Nakamura H, Fang J (2013) The EPR effect for macromolecular drug delivery to solid tumors: Improvement of tumor uptake, lowering of systemic toxicity, and distinct tumor imaging in vivo. Adv Drug Deliv Rev 65(1): 71-79.

20. BrownJM, Wilson WR (2004) Exploiting tumour hypoxia in cancer treatment. Nat Rev Cancer 4(6): 437-447.

21. Theys J, Nuyts S, Landuyt W, Van Mellaert L, Dillen C, et al. (1999) Stable Escherichia coli-Clostridium acetobutylicum shuttle vector for secretion of murine tumor necrosis factor alpha. Appl Environ Microbiol 65(10): 4295-4300.

22. Pawelek JM, Low KB, Bermudes D (1997) Tumor-targeted Salmonella as a novel anticancer vector. Cancer Res 57 (20): 4537-4544.

23. Fang J, Liao L, Yin H, Nakamura H, Shin T, et al. (2014) Enhanced bacterial tumor delivery by modulating the EPR effect and therapeutic potential of Lactobacillus casei. J Pharm Sci 103(10): 3235-3243.

24. Brancaccio VF, Zhurina DS, Riedel CU (2013) Tough nuts to crack. Site-directed mutagenesis of bifidobacteria remains a challenge. Bioengineered 4(4): 197-202.

25. Missich R, Sgorbati B, LeBlanc DJ (1994) Transformation of Bifidobacterium longum with $\mathrm{pRM} 2$, a constructed Escherichia coli-B. longum shuttle vector. Plasmid 32(2): 208-211.

26. Serafini F, Turroni F, Guglielmetti S, Gioiosa L, Foroni E, et al. (2012) An efficient and reproducible method for transformation of genetically recalcitrant bifidobacteria. FEMS Microbiol Lett 333(2): 146-152.

27. Sakaguchi K, He J, Tani S, Kano Y, Suzuki T (2012) A targeted gene knockout method using a newly constructed temperature-sensitive plasmid mediated homologous recombination in Bifidobacterium longum. Appl Microbiol Biotechnol 95(2): 499-509.

28. Matsumura H, Takeuchi A, Kano Y (1997) Construction of Escherichia coli-Bifidobacterium longum shuttle vector transforming $B$. longum 105-A and 108-A. Biosci Biotechnol Biochem 61(7): 1211-1212.

29. Taniguchi S, Shimatani Y, Fujimori M (2016) Tumor-Targeting Therapy Using Gene-Engineered Anaerobic-Nonpathogenic Bifidobacterium longum. Methods Mol Biol 1409: 49-60.

30. Pastan I, Hassan R, Fitzgerald DJ, Kreitman RJ (2006) Immunotoxin therapy of cancer. Nat Rev Cancer 6(7): 559-565.

31. U Brinkmann, I Pastan, (1994) Immunotoxins against cancer. Biochim Biophys Acta 1198(1): 27-45.

32. Michalska M, Wolf P (2015) Pseudomonas Exotoxin A: optimized by evolution for effective killing. Front Microbiol 6: 963.

33. Sircar A, Sanni KA, Shi J, Gray JJ (2011) Analysis and modeling of the variable region of camelid single-domain antibodies. J Immunol 186(11): 6357-6367.

34. Normanno N, Maiello MR, De Luca A (2003) Epidermal growth factor receptor tyrosine kinase inhibitors (EGFR-TKIs): simple drugs with a complex mechanism of action? J Cell Physiol 194(1): 13-19.

35. Tan X, Lambert PF, Rapraeger AC, Anderson RA (2016) Stress-Induced EGFR Trafficking: Mechanisms, Functions, and Therapeutic Implications. Trends Cell Biol 26(5): 352-366.

36. Taira Y, Ishida I (2018) Antitumor agent, marker for tumor detection, and oral vaccine agent.

37. Wakeling AE, Guy SP, Woodburn JR, Ashton SE, Curry BJ, et al. (2002) ZD1839 (Iressa): an orally active inhibitor of epidermal growth factor signaling with potential for cancer therapy. Cancer Res 62(20): 57495754.

38. de Miguel D, Lemke J, Anel A, Walczak H, Martinez Lostao L (2016) Onto better TRAILs for cancer treatment. Cell Death Differ 23(5): 733-747.

39. Ukrainskaya VM, Stepanov AV, Glagoleva IS, Knorre VD, Belogurov AAJ, et al. (2017) Death Receptors: New Opportunities in Cancer Therapy. Acta Naturae 9(3): 55-63.

40. Papadopoulos KP, Isaacs R, Bilic S, Kentsch K, Huet HA, et al. (2015) Unexpected hepatotoxicity in a phase I study of TAS266, a novel tetravalent agonistic Nanobody ${ }^{\circledR}$ targeting the DR5 receptor. Cancer Chemother Pharmacol 75(5): 887-895.

41. Mori E, Thomas M, Motoki K, Nakazawa K, Tahara T, et al. (2004) Human normal hepatocytes are susceptible to apoptosis signal mediated by both TRAIL-R1 and TRAIL-R2. Cell Death Differ 11(2): 203-207. 
42. Nishikawa T, Taira Y, Taira I, Ishida I (2016) Recombinant anaerobic gram-positive bacteria.

43. (2017) Health and Medical Services. "Annual Health, Labour and Welfare Report 2017", Japanese Ministry of Health, Labor and Welfare, Japan. pp. 102.

44. (2018) European Federation of Pharmaceutical Industries and Associations. The Pharmaceutical Industry in Figures Key Data, Europe.

45. Shapiro J, Price VH (1998) Hair regrowth. Therapeutic agents. Dermatol Clin 16(2): 341-356.

ISSN: 2574-1241

DOI: 10.26717/BJSTR.2019.12.002324

Ikuko Taira. Biomed J Sci \& Tech Res

(c) (P) This work is licensed under Creative

Submission Link: https://biomedres.us/submit-manuscript.php
46. Goldstein I, Lue TF, Padma Nathan H, Rosen RC, Steers WD, et al. (1998) Oral sildenafil in the treatment of erectile dysfunction. Sildenafil Study Group. N Eng J Med 338 (20): 1397-1404.

47. Francisco JA, Cerveny CG, Meyer DL, Mixan BJ, Klussman K, et al. (2003) cAC10-vcMMAE, an anti-CD30-monomethyl auristatin E conjugate with potent and selective antitumor activity. Blood 102(4): 1458-1465.

48. Erickson HK, Park PU, Widdison WC, Kovtun YV, Garrett LM, et al. (2006) Antibody-maytansinoid conjugates are activated in targeted cancer cells by lysosomal degradation and linker-dependent intracellular processing. Cancer Res 66(8): 4426-4433.

$\begin{array}{ll}\text { BIOMEDICAL } & \text { Assets of Publishing with us } \\ \text { RESEARCHES } & \text { - Global archiving of articles } \\ & \text { - Immediate, unrestricted online access } \\ & \text { - Rigorous Peer Review Process } \\ & \text { - Authors Retain Copyrights } \\ \end{array}$

